\title{
Surgical management of complete penile duplication accompanied by multiple anomalies
}

\author{
Irfan Karaca, MD; ${ }^{*}$ Erdal Turk, MD; ${ }^{*}$ A. Basak Ucan, MD; Derya Yayla, MD; ${ }^{\dagger}$ Gulcin Itirli, MD; ${ }^{\ddagger}$ Derya Ercal, MD* \\ *Department of Pediatric Surgery, Faculty of Medicine, Izmir University, Izmir, Turkey; 'Departments of Pediatric Surgery, Dr. Behcet Uz Children's Hospital, Izmir/Turkey; ${ }^{\circledR}$ Department of Biology, Faculty \\ of Science, Izmir University, Izmir, Turkey; ' DDivisions of Genetics, Department of Pediatrics, Dokuz Eylül University Faculty of Medicine, Izmir, Turkey
}

Cite as: Can Urol Assoc J 2014;8(9-10):e741-3. http://dx.doi.org/10.5489/cuaj.2049 Published online October 22, 2014.

\section{Abstract}

Diphallus (penile duplication) is very rare and seen once every 5.5 million births. It can be isolated, but is usually accompanied by other congenital anomalies. Previous studies have reported many concurrent anomalies, such as bladder extrophy, cloacal extrophy, duplicated bladder, scrotal abnormalities, hypospadias, separated symphysis pubis, intestinal anomalies and imperforate anus; no penile duplication case accompanied by omphalocele has been reported. We present the surgical management of a patient with multiple anomalies, including complete penile duplication, hypogastric omphalocele and extrophic rectal duplication.

\section{Introduction}

Penile duplication (diphallus) is rare and seen in about 1 in of every 5.5 million live births; there are 100 reported cases. ${ }^{1}$ It is mainly divided into 4 classes: complete, incomplete, bifida, and pseudo diphallus. ${ }^{2,3}$ Previous studies have reported many concurrent anomalies, such as bladder extrophy, cloacal extrophy, duplicated bladder, scrotal abnormalities, hypospadias, separated symphysis pubis, intestinal anomalies and imperforate anus; no penile duplication case accompanied by omphalocele has been reported. ${ }^{4}$ The large variability in the degree of duplication and the number and type of additional anomalies in such patients leads to different surgical approaches for each patient. ${ }^{5}$

In this study, we present the surgical method used in a patient with complete penile duplication, hypogastric omphalocele, rectal duplication, extrophy variant, bladder duplication, proximal hypospadias, anal stenosis, undescended testes and bifida scrotum.

\section{Case report}

The infant was born at 37 weeks with a birthweight of $1800 \mathrm{~g}$; the birth was a Cesearean section with a 30-yearold mother with a history of smoking and 4 previous stillbirths. The male infant was referred to our hospital with omphalocele and suspect genital structure. The physical examination revealed hypogastric omphalocele, extrophy variant, complete diphallus, bilateral undescended testes, bifid scrotum and anal stenosis (Fig. 1, part A). The karyotype was $46 \mathrm{XY}$. After preoperative preparations, the patient was taken to surgery on the second day of his life. Both orifices at the proximal penis proximal were catheterized during surgery. There was another orifice present on the mucosal surface of the structure located between the two penises and was thought to be ectopic intestinal tissue. This location was catheterized; this area was understood to be a blunt-ended structure 4 to $5 \mathrm{~cm}$ in length and a biopsy was obtained. Duplicated bladder tissue expanding to the right half of the right kidney and the left half of the left kidney was present right below this structure (Fig. 1, part B). Ureteral orifices were catheterized separately. After the hypogastric omphalocele was primarily repaired, posterior anoplasty was performed for the anal stenosis (Fig. 1, part C). The histopathological examination of the biopsy specimen taken from the patient was reported as large intestine material with a surface covered with eroded colonic epithelium and immature ganglion cells in the plexi of the muscular layer.

The patient underwent a second surgery 2 years later for reconstruction and the ectopic colonic tissue was understood to be a blunt-ended duplicated segment about $7 \mathrm{~cm}$ in length. Pelvic osteotomy-assisted cystoplasty was performed after the excision of this tissue. The penis located on the right was less developed than the penis located on the left. The penis on the right was excised and phalloplasty was performed for the left penis causing the penis to take on the appearance of proximal hypospadias. After bilateral orchido- 


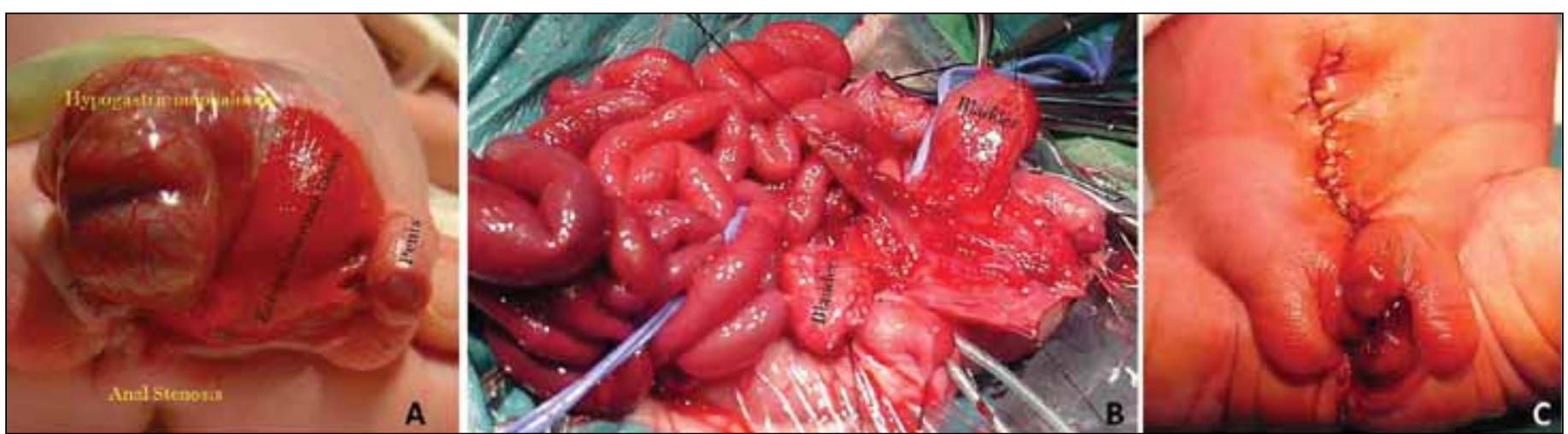

Fig. 1. The patient before, during and after the initial operation.

pexy for the intra-abdominal testes, the anterior abdominal wall was primarily closed (Fig. 2, parts A, B). The pathology result of the blunt-ended intestinal segment was tubular rectal duplication. Tubularized insert plate urethroplasty was performed for the penoscrotal hypospadias when the patient was 8 years old (Fig. 3, parts A, B, C). Scrotoplasty is planned for the patient when he becomes 10 years old with full anal continence. However, there is intermittent urinary incontinence and a simultaneous bladder neck injection is planned.

\section{Discussion}

The most common additional anomalies are intestinal and genitourinary tract anomalies in cases of complete diphallus. The most common intestinal tract abnormality is imperforate anus, and the least common is rectal duplication that may be tubular or cystic in structure. ${ }^{4-6}$ No omphalocele association has been reported. Our case is the first reported case with the complete penile duplication and omphalocele association and the presence of rectal duplication in tubular structure. Treatment of diphallus usually includes excision of the duplicated penile structure and its urethra. Associated anomalies can also be repaired surgically., ${ }^{5,6}$ The prognosis usually correlates with the general condition of the patient and the severity of the anomalies. ${ }^{5-7}$ We believe that the lack of involvement in vital organs, such as the heart and lungs by the other anomalies seen in our patient, had a positive impact on the prognosis.

The karyotype of cases with a diphallus anomaly is usually normal, and the only exception is the balanced translocation $\mathrm{t}(1,14)$ (p36.3; q24.3) case. $^{8}$ Karyotype analysis performed on our patient was normal. Chemical or genetic effects may occur in the Homeobox (HOX) family of transcription factors; these are important in early embryonic development and regulate several target genes for the formation of many body structures. These genes include BMP-4,

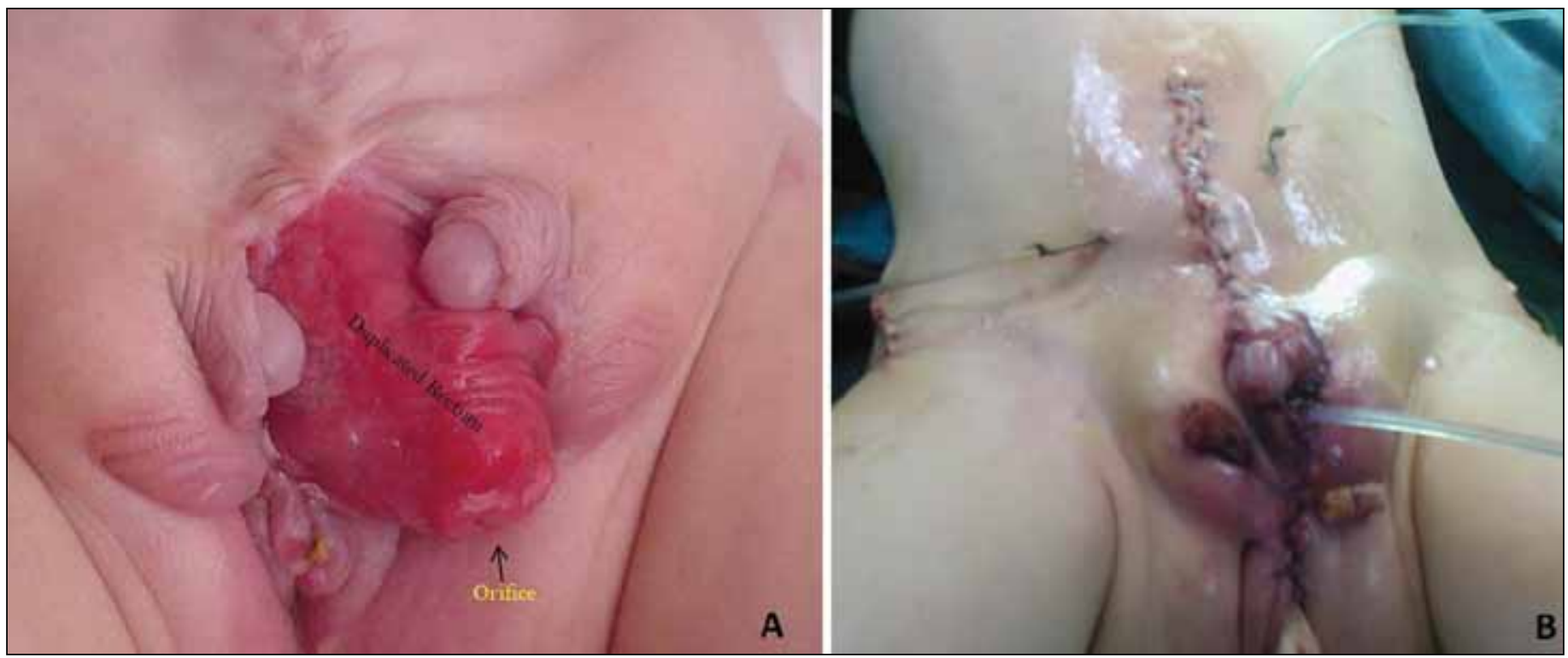

Fig. 2. The patient before and after the second operation (after 2 years). 


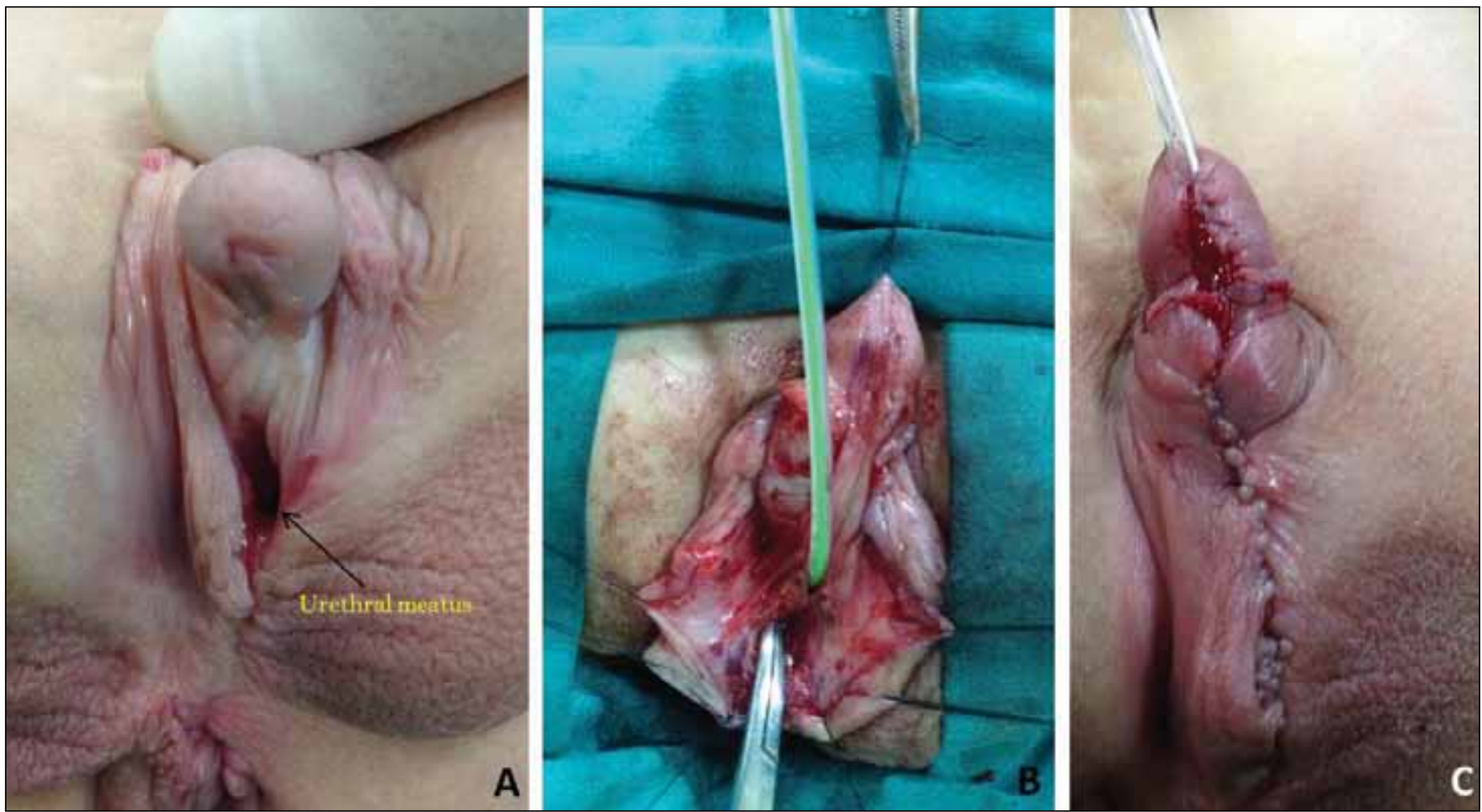

Fig. 3. The patient before and after the third operation - primary repair of the proximal hypospadias with the tubularized insert plate urethroplasty method (after 8 years).

FOXC-1, WT-1, SOX-9 and SF-1. When HOX genes cannot provide the required control, development is impaired and problems may occur when the caudal cell mass in the mesoderm is divided from the genital tubercle and rectum in the urogenital sinus to form the penis with the influence of the affected genes. ${ }^{9,10}$ Mutations in these genes can cause related syndromes associated with diphallus. ${ }^{10,11}$

\section{Conclusion}

The surgical treatment of penile duplication patients planned should be specific for each patient according to the degree of penile duplication and additional anomalies so as to preserve continence and erectile functions.

Competıng interests: Dr. Karaca, Dr. Turk, Dr. Ucan, Dr. Yayla, Dr. Itirli and Dr. Ercal all declare no competing financial or personal interests.

This paper has been peer-reviewed.

\section{References}

1. Rao TV, Chandrasekharam V. Diphallus with duplication of cloacal derivatives: Report of a rare case. J Urol 1980;124:555-7.

2. Tepeler A, Karadag MA, Özkuvancı Ü, et al. Complete diphallus in a 14 years old boy. Marmara Med J 2007;20:190-2.

3. Vilanova X, Raventos A. Pseudodiphallia, a rare anomaly. J Urol 1954;71:338-46.

4. Dewan PA, Lawrence MJ, Pip A, et al. Diphallus associated with partial caudal duplication. Pediatr Surg Int 1998;14:131-3. http://dx.doi.org/10.1007/s003830050461

5. Mirshemirani AR, Sadeghyian N, Mohajerzadeh L, et al. Diphallus: Report on six cases and review of the literature. Iran J Pediatr 2010;20:353-7.

6. Bakheet MA, Refaei M. Penile duplication and two anal openings: Report of a very rare case. Iran J Pediatr 2012;22:133-6.

7. Kardasevic M, Begic F, Sivic M. Penile duplication in newborn with multiple anomalies. Med Arh 2012;66:206-8. http://dx.doi.org/10.5455/medarh.2012.66.206-208

8. Karna $P$, Kapur $S$. Diphallus and associated anomalies with balanced autosomal chromosomal translocation. Clin Genet 1994;46:209-11. http://dx.doi.org/10.1111/i.1399-0004.1994.tb04226.x

9. Gyftopoulos K, Wolffenbuttel KP, Niiman RJ. Clinical and embryologic aspects of penile duplication and associated anomalies. Urology 2002;60:675-9.

10. MacLaughlin DT, Donahoe PK. Sex determination and differentiation. N Eng/J Med 2004;350:367-78.1

11. Baipai M, Das K, Gupta AK. Caudal duplication syndrome: More evidence for theory of caudal twinning. J Pediatr Surg 2004:39:223-5.

Correspondence: Dr. Erdal Turk, Yeni Girne Bulvarn 1825 Sok., No:12, 35530 Karsiyaka/lzmir; eturk19@yahoo.de 